\title{
Role of Parents in Adolescent Sexual Activity And Contraceptive Use in Four African Countries
}

\section{By Ann Biddlecom, \\ Kofi Awusabo- \\ Asare and \\ Akinrinola Bankole}

Ann Biddlecom is senior research associate, and Akinrinola Bankole is director of international research, both at the Guttmacher

Institute, New York. Kofi Awusabo-Asare is professor, Department of Population and

Health, University of Cape Coast, Cape Coast, Ghana.
CONTEXT: Parents have an influence on the sexual and reproductive health of adolescents, but evidence from SubSaharan Africa is limited. A better understanding of the relationship between different dimensions of parenting and recent sexual activity and contraceptive use is needed in the region.

METHODS: Data were collected in 2004 in nationally representative surveys of 12-19-year-olds in Burkina Faso, Ghana, Malawi and Uganda. Bivariate analysis compared gender differences for two outcomes among unmarried 15-19-year-olds - having had sexual intercourse in the last 12 months and, among those who had had sex in this period, contraceptive use at last sex. Multivariate logistic regression analysis identified associations between these outcomes and coresidence with parents or parent figures, parental monitoring and parent-child communication.

RESULTS: Unmarried adolescents reported moderate to high levels of parental monitoring and low levels of parentchild communication about sexual matters. In all countries, adolescent males who reported low monitoring were at elevated risk of having had sex in the last year (odds ratios, 2.4-5.4), as were their female counterparts in three of the countries (6.9-7.7). Communication with parents was positively associated with sexual activity among Malawian males and Ugandan females (2.2 and 1.5, respectively). Parental monitoring was not associated with contraceptive use at last sex, whereas parent-child communication was associated with such use among Ghanaian females (3.0) and among Ugandan adolescents of both genders (1.9-2.0).

CONCLUSIONS: Programs to improve adolescent sexual and reproductive health should include dimensions of parental involvement that can strengthen the program's specific behavior change goals.

International Perspectives on Sexual and Reproductive Health, 2009, 35(2):72-81
Parents and parent figures-adults whom adolescents describe as being like a mother or father to them-play important roles in the lives of adolescents. Various studies have examined the influence that types of parenting have on the behaviors of young people, including risk-taking behavior. ${ }^{1-3}$ Parents are expected to monitor their children's activities, as well as identify, sift and package information and services for their children. Because parents are in regular contact with children, they help to shape both their behavior and the social context in which they grow up. Given the different ways that parents can influence their children, school-and community-based sex and family life education programs have been challenged to make parents aware of their services and seek their support; evidence suggests that programs are more likely to be successful if they include such communitybased components. ${ }^{4}$

\section{BACKGROUND}

There is a growing literature on the role of parents regarding adolescent sexual and reproductive health worldwide, including Sub-Saharan Africa. ${ }^{2}$ Moreover, international and nongovernmental organizations have begun to implement activities that explicitly address the role of parents in improving adolescent sexual and reproductive health: More than 30 such programs were recently described in a review by the World Health Organization. ${ }^{5}$ Some programs, such as Uganda's Straight Talk campaign, have demonstrated the general willingness of parents and other adults to create a supportive environment for young people. These programs may include the provision of sexual and reproductive health information and services, even if parents themselves feel uncomfortable talking directly with adolescents about these issues. ${ }^{6,7}$ Other programs, such as Families Matter! in Kenya, work directly with parents and their children to improve intrafamily communication about sexuality and sexual risk. ${ }^{8}$

There is growing evidence that various parenting dimensions-connectedness or love, material support, behavioral control or monitoring, and parent-child communication-are positively associated with reduced levels of risk-taking behavior among adolescents. The association often varies by the measures employed, and by other issues such as gender (e.g., whether the adult or young person is male or female) and normative roles and attitudes.

Some studies support the proposition that adolescents are less likely to engage in sexual risk-taking behavior when they reside with a parent-especially two parents-or when they identify with the views of their parents. ${ }^{1,9,10} \mathrm{~A}$ survey-based study in a slum in Nairobi, Kenya, found that 
when a father lived in the same household as his nevermarried 12-19-year-old daughters, they were much less likely to have ever had sex, to have had an unwanted pregnancy or to have been recently sexually active than when neither parent or only the mother lived in the household. ${ }^{11}$ In Ghana, national survey data showed that adolescent females who lived with both parents were less likely than females who had other living arrangements to have ever had sex, but the same was not found for males, and there was no association with number of sexual partners or contraceptive use for either gender. ${ }^{12}$ Another study in Ghana found no protective effect on recent sexual activity of living with both parents versus none, although boys were less likely to be sexually active if they lived with their mother and more likely if they lived with their father (versus no parent). ${ }^{13} \mathrm{~A}$ study in Côte d'Ivoire found that female adolescents (but not males) who had lived in the same household as their father during childhood were more likely than those who had not to delay first sex. ${ }^{14}$

Other studies have shown strong evidence of parental monitoring and reduced sexual risk-taking behavior among adolescents, mostly in developed countries. For example, in a prospective cohort study of 14-19-year-old African Americans, high levels of parental supervision were associated with reduced incidence of gonorrhea and chlamydia (after adjusting for age and baseline infection). ${ }^{15}$ Two studies of adolescents in low-income neighborhoods in the United States also found negative associations between parental monitoring and STIs ${ }^{16}$ and sexual risk behaviors (such as having multiple sexual partners or not using a condom at last sex). ${ }^{10,16}$ Using national longitudinal data from early adolescence (12-14) into early adulthood (19-21), another U.S. study documented no effect of parental monitoring behavior on early onset of sex among either females or males, although monitoring was associated with males having fewer sex partners in early adulthood. ${ }^{17}$ Furthermore, a longitudinal study of teenagers in Scotland (aged 13-14 at baseline and 15-16 at follow-up) found that low parental monitoring was associated with an earlier transition to sexual activity for both females and males, and also with a greater risk of unprotected sex for females. ${ }^{3}$

Another dimension of parenting is communication. In Sub-Saharan Africa, available evidence suggests that parent-child communication about sex-related matters is not very common and at times is fraught with discomfort, especially communication with fathers. ${ }^{7,18}$ Furthermore, the association between communication and adolescent sexual behavior and risk outcomes is not consistent. In Côte d'Ivoire, parent-child communication about abstinence had opposite associations among daughters (later initiation of first sex) and among sons (earlier initiation). ${ }^{14}$ Two of the studies described earlier contrasted parental monitoring with parental communication, and concluded that communication did not play a role, or at best played a very weak role, in adolescent sexual activity compared with the other parenting dimensions. ${ }^{3,15}$ However, few studies have tested the relationship of both family communication and monitoring with adolescent sexual behavior in Sub-Saharan countries. The present study examines three dimensions of parentingmaterial support (measured as coresidence with parents or parent figures), monitoring and communication-and seeks to contribute to the search for strategies to involve parents most effectively in improving the sexual and reproductive health of their adolescent children.

\section{Study Settings}

The study is based on data from nationally representative surveys of 15-19-year-olds in four African countries (Burkina Faso, Ghana, Malawi and Uganda) that are part of a research project known as Protecting the Next Generation: Understanding HIV Risk Among Youth. The countries, selected to represent different subregions of Sub-Saharan Africa (West, East and Southern) and to span the range of HIV prevalence in the region, include one francophone country (Burkina Faso). In 2007, the estimated HIV prevalence rate in Sub-Saharan Africa among 15-24-year-olds was 3.2\% among women and $1.1 \%$ among men. ${ }^{19}$ In West Africa, Ghana and Burkina Faso have comparatively low HIV levels in this age-group $0.4 \%$ and $0.5 \%$ among males, respectively, and $1.3 \%$ and $0.9 \%$ among females, respectively). ${ }^{19}$ Uganda and Malawi, in East and Southern Africa, respectively, have been harder hit by the AIDS epidemic: Estimated 2007 HIV prevalence levels were 1.3\% and $2.4 \%$ among young men, and $3.9 \%$ and $8.4 \%$ among young women, respectively. ${ }^{19}$

The four countries also represent slightly different sexual and reproductive profiles of adolescents. For example, females tend to marry early in all the countries except Ghana: Among 20-24-year-olds, 54\% have married by age 18 in Uganda, 52\% in Burkina Faso and 47\% in Malawi, but only $28 \%$ in Ghana. ${ }^{20}$ About one in three young women in Malawi and Uganda, and about one in four in Burkina Faso and Ghana, have experienced premarital sex before age $18 .{ }^{20}$ Among adolescent males who have had sex during adolescence, the majority have done so before marriage, given their much later age at marriage, on average. Levels of contraceptive use among young people in the region have improved slowly, but there has been a notable increase in condom use. ${ }^{21}$ Overall, the percentage of sexually active, unmarried young women aged 15-24 who currently use modern contraceptives is $25 \%$ in Malawi, $33 \%$ in Ghana, 34\% in Uganda and 56\% in Burkina Faso. ${ }^{22}$ Given that these four countries reflect different subregions with different HIV, sexual behavior and contraceptive use patterns among adolescents, the extent to which we observe similar associations between parental roles and adolescent sexual behavior and contraceptive use will increase our understanding of these issues for the region as a whole.

As mentioned earlier, some programs in these countries have involved parents in efforts to improve adolescent sexual and reproductive health. ${ }^{5}$ In Burkina Faso and Malawi, programs have focused on improving parent-child com- 
munication around sexual and reproductive health. In Burkina Faso, the intervention activities were wideranging, with parents helping to identify reproductive health needs and being sensitized to other program activities in the community (e.g., the role of peer educators). In Malawi, the intervention focused exclusively on improving parent-child communication with younger adolescents (aged 7-11) by training parents how to use a structured guide once a week so they could have conversations with their children. In contrast, a program in Uganda focused on improving adolescent girls' sexual and reproductive health knowledge, including strategies to delay sexual intercourse and other methods of HIV prevention. This program also trained adult women in taking on the role of senga (the father's sister, the child's paternal aunt), a person who traditionally provides this type of information.

\section{METHODS}

Data are from nationally representative, household-based surveys of female and male 12-19-year-olds conducted in 2004 in Burkina Faso, Ghana, Malawi and Uganda. * The surveys were designed to be as comparable as possible and to include a wide range of measures of family context. A twostage, cluster sample design was used: In the first stage, approximately 200 enumeration areas were selected within each country, and in the second stage, 27-48 households per area were chosen from a household list. All de facto residents in each sampled household were eligible for inclusion in the survey. We sought informed consent directly from 18-19-year-olds; for adolescents younger than 18, we obtained consent from a parent or guardian before approaching the eligible adolescents for assent to participate in the survey. Interviews were completed with 5,955 adolescents in Burkina Faso, 4,430 in Ghana, 4,031 in Malawi and 5,112 in Uganda. The overall individual response rate ranged between 87\% (Uganda) and 95\% (Burkina Faso). 23-26

Because of low levels of self-reported sexual intercourse among 12-14-year-olds ${ }^{27}$ and a relatively fast transition to first sex among older adolescents, our analysis was restricted to adolescents who were 15-19 years old at the time of the survey. We excluded married adolescents because they are assumed to be sexually active and they are more likely to be living with and under the influence of a spouse rather than parents or parent figures. The analysis was based on 2,948 respondents from Burkina Faso, 2,426 from Ghana, 2,025 from Malawi and 2,363 from Uganda. Having had sexual intercourse in the 12 months prior to the interview and having used any contraceptive method at last sex (among those who had had sex in the last 12 months) were the two dependent variables.

The key independent variables were coresidence with biological parents or parent figures, an index of perceived parental monitoring and two measures of perceived

*Four districts in northern Uganda were dropped from the sample because of security concerns during fieldwork. The four country surveys are available for research use at <http://www.icpsr.umich.edu/cocoon/ ICPSR/SERIES/00227.xml>. parental communication about sex-related matters. Coresidence was measured as a four-category variable-residing in the same household with both parents or parent figures, with mother or mother figure only, with father or father figure only, or with no parents or parent figures-and indicated the physical presence of a significant parent figure in the life of an unmarried adolescent. Adolescents who reported that their biological mother or father had died were asked whether there was someone who was like a mother or father to them, and if so, whether that person lived in the household; such adults were coded as "parent figures."

The index of parental monitoring was based on an adolescent's perception of parent or parent figure knowledge on three different questions: where the adolescent goes at night, what the adolescent does with his or her free time, and who the adolescent's friends are. These questions explicitly mentioned parents and parent figures, so it included adults who, though not the biological parents of the adolescent, were in effect assuming parental roles for the adolescent. Each question had three response categories: parent or parent figure does not know (one point), sometimes knows (two points) or always knows (three points). Because there was some evidence of collinearity among these three measures in Burkina Faso and Ghana, the values for each were summed to create a monitoring index that was classified as low (3-5 points), medium (6-8 points) or high (nine points). Among female adolescents, the mean ranged from 7.4 in Malawi to 7.9 in Ghana, and among male adolescents, from 6.7 in Uganda to 7.3 in Ghana (not shown).

The first of the two measures of parent-child communication was an open-ended question that asked which types of people had talked to the adolescent about "sexrelated matters." This phrase was purposefully kept vague because prior questions had been about specific areas of reproductive health, and an additional measure was needed about general issues of an intimate nature. The question was preceded by a statement that this and the next question referred to people who may have talked to the respondent about personal things.

The second measure of parent-child communication was an open-ended question that asked about the types of people or other sources from which the adolescent received information about contraceptive methods. The question did not specify types of methods (e.g., condoms versus other methods) or the nature of the information (e.g., how to use methods, health side effects or effectiveness). However, it did specify pregnancy prevention and not the prevention of STIs or HIV, for which condoms play a critical role.

Background characteristics included age, current school attendance, frequency of attendance at religious services (less than once a week, once a week and more than once a week), urban or rural residence, and the wealth quintile of the adolescent's household. The last measure was constructed from responses to questions regarding about 20 household assets, services and amenities, and quintiles were based on the wealth status of all households in the na- 


\begin{tabular}{|c|c|c|c|c|c|c|c|c|}
\hline \multirow[t]{2}{*}{ Variable } & \multicolumn{2}{|c|}{ Burkina Faso } & \multicolumn{2}{|c|}{ Ghana } & \multicolumn{2}{|c|}{ Malawi } & \multicolumn{2}{|c|}{ Uganda } \\
\hline & $\begin{array}{l}\text { Female } \\
(\mathrm{N}=1,279)\end{array}$ & $\begin{array}{l}\text { Male } \\
(\mathrm{N}=1,669)\end{array}$ & $\begin{array}{l}\text { Fema } \\
(\mathrm{N}=1\end{array}$ & $\begin{array}{l}\text { Male } \\
(\mathrm{N}=1,250)\end{array}$ & $\begin{array}{l}\text { Fem } \\
(\mathrm{N}=8\end{array}$ & $\begin{array}{l}\text { Male } \\
(\mathrm{N}=1,135)\end{array}$ & $\begin{array}{l}\text { Fema } \\
(\mathrm{N}=1\end{array}$ & $\begin{array}{l}\text { Male } \\
(\mathrm{N}=1,288)\end{array}$ \\
\hline \multicolumn{9}{|l|}{ DEPENDENT } \\
\hline Yes & 22.8 & 24.8 & 17.4 & 10.0 & 18.0 & 37.1 & 23.7 & 30.4 \\
\hline No & 77.2 & 75.2 & 82.6 & 90.0 & 82.0 & 62.9 & 76.3 & 69.6 \\
\hline \multicolumn{9}{|l|}{ Used contraceptive at last sex† } \\
\hline Yes & 55.1 & 51.1 & 55.6 & 52.8 & 36.9 & 40.8 & 49.9 & 56.1 \\
\hline No & 44.9 & 48.9 & 44.4 & 47.2 & 63.1 & 59.2 & 50.1 & 43.9 \\
\hline \multicolumn{9}{|l|}{ INDEPENDENT } \\
\hline Living arrangement & \multicolumn{2}{|l|}{$* *$} & \multicolumn{2}{|c|}{$* * *$} & & & & \\
\hline With both parents/parent figures & 54.9 & 59.7 & 40.7 & 41.8 & 42.3 & 45.2 & 39.9 & 40.9 \\
\hline With mother only & 9.2 & 9.8 & 24.3 & 23.2 & 21.1 & 20.1 & 18.9 & 19.3 \\
\hline With father only & 5.7 & 8.7 & 4.4 & 8.9 & 5.1 & 4.8 & 9.7 & 10.3 \\
\hline With none & 30.1 & 21.9 & 30.7 & 26.2 & 31.5 & 29.9 & 31.5 & 29.4 \\
\hline Parents/parent figures know where adolescent goes at night & \multicolumn{2}{|l|}{$* * *$} & \multicolumn{2}{|c|}{$* * *$} & \multicolumn{2}{|c|}{$* * *$} & \multicolumn{2}{|c|}{$* * *$} \\
\hline No & 7.4 & 17.8 & 6.3 & 10.7 & 18.9 & 30.4 & 12.3 & 24.3 \\
\hline Sometimes & 17.7 & 30.1 & 19.6 & 31.5 & 21.5 & 25.2 & 16.7 & 30.5 \\
\hline Always & 74.9 & 52.2 & 74.1 & 57.8 & 59.6 & 44.4 & 71.0 & 45.2 \\
\hline \multicolumn{3}{|l|}{ Parents/parent figures know what adolescent does with free time } & \multicolumn{2}{|c|}{ *** } & & & & \\
\hline No & 9.6 & 15.4 & 6.9 & 10.8 & 18.1 & 19.1 & 12.7 & 18.8 \\
\hline Sometimes & 37.5 & 50.6 & 23.0 & 38.2 & 22.7 & 34.7 & 23.5 & 38.4 \\
\hline Always & 52.9 & 34.0 & 70.0 & 51.0 & 59.2 & 46.2 & 63.9 & 42.8 \\
\hline Parents/parent figures know who adolescent's friends are & ** & & & & & & & \\
\hline No & 9.2 & 7.8 & 8.4 & 9.2 & 13.5 & 12.1 & 17.6 & 17.9 \\
\hline Sometimes & 22.7 & 28.9 & 22.4 & 36.9 & 16.2 & 42.0 & 22.5 & 42.3 \\
\hline Always & 68.1 & 63.4 & 69.2 & 53.9 & 70.3 & 45.9 & 60.0 & 39.9 \\
\hline Parent/parent figure monitoring & $* * *$ & & & & & & & \\
\hline Low & 8.9 & 16.4 & 6.7 & 11.4 & 16.8 & 25.5 & 15.0 & 24.1 \\
\hline Medium & 48.6 & 59.1 & 40.6 & 57.2 & 43.2 & 53.4 & 38.8 & 53.7 \\
\hline High & 42.5 & 24.5 & 52.7 & 31.4 & 40.0 & 21.1 & 46.3 & 22.2 \\
\hline $\begin{array}{l}\text { Parents/parent figures ever talked to adolescent about } \\
\text { sex-related matters }\end{array}$ & $* * *$ & & & & & & & \\
\hline Yes & 13.5 & 7.7 & 37.9 & 22.3 & 30.5 & 25.6 & 38.1 & 19.6 \\
\hline No & 86.5 & 92.3 & 62.1 & 77.7 & 69.5 & 74.4 & 61.9 & 80.4 \\
\hline $\begin{array}{l}\text { Parents/parent figures ever gave information about } \\
\text { contraceptive methods }\end{array}$ & *** & & & & & *** & & \\
\hline Yes & 5.1 & 1.3 & 8.0 & 5.8 & 10.1 & 5.1 & 23.6 & 7.8 \\
\hline No & 94.9 & 98.7 & 92.0 & 94.2 & 89.9 & 94.9 & 76.4 & 92.2 \\
\hline Age & $* * *$ & & & & & & & \\
\hline 15 & 31.5 & 26.1 & 26.4 & 26.5 & 24.9 & 25.3 & 29.0 & 25.7 \\
\hline 16 & 26.8 & 20.1 & 24.3 & 19.4 & 24.9 & 20.7 & 24.7 & 22.5 \\
\hline 17 & 19.7 & 20.2 & 20.0 & 22.2 & 22.5 & 18.7 & 18.3 & 19.4 \\
\hline 18 & 13.1 & 18.9 & 17.7 & 20.2 & 17.1 & 18.9 & 17.6 & 19.1 \\
\hline 19 & 8.9 & 14.7 & 11.6 & 11.8 & 10.6 & 16.5 & 10.4 & 13.4 \\
\hline Currently in school & & & & & & & & \\
\hline Yes & 20.7 & 21.8 & 60.9 & 66.8 & 63.2 & 68.8 & 61.3 & 66.4 \\
\hline No & 79.3 & 78.2 & 39.1 & 33.2 & 36.8 & 31.2 & 38.7 & 33.6 \\
\hline Frequency of religious attendance & *** & & & & & & & \\
\hline <once a week & 44.0 & 36.4 & 8.5 & 15.4 & 3.6 & 4.2 & 8.3 & 12.6 \\
\hline Once a week & 25.4 & 25.6 & 47.2 & 47.6 & 68.0 & 67.5 & 75.5 & 65.7 \\
\hline >once a week & 30.7 & 38.1 & 44.3 & 36.9 & 28.4 & 28.4 & 16.2 & 21.7 \\
\hline Residence & $* * *$ & & & & & & & \\
\hline Urban & 35.9 & 24.4 & 51.9 & 46.4 & 25.2 & 24.3 & 15.5 & 11.3 \\
\hline Rural & 64.1 & 75.6 & 48.1 & 53.6 & 74.8 & 75.7 & 84.5 & 88.7 \\
\hline Household wealth index & $* * *$ & & & & & & & \\
\hline Poorest & 14.9 & 14.4 & 14.9 & 16.6 & 20.6 & 15.8 & 17.2 & 18.1 \\
\hline Second & 17.1 & 19.7 & 17.1 & 20.3 & 14.7 & 21.6 & 18.6 & 21.1 \\
\hline Third & 15.9 & 20.0 & 20.0 & 20.6 & 17.4 & 20.9 & 17.1 & 21.0 \\
\hline Fourth & 15.5 & 21.3 & 21.6 & 21.9 & 23.7 & 19.0 & 20.8 & 19.5 \\
\hline Wealthiest & 36.6 & 24.7 & 26.4 & 20.6 & 23.7 & 22.8 & 26.3 & 20.3 \\
\hline
\end{tabular}




\begin{tabular}{|c|c|c|c|c|c|c|c|c|}
\hline \multirow[t]{2}{*}{ Variable } & \multicolumn{2}{|c|}{ Burkina Faso } & \multicolumn{2}{|l|}{ Ghana } & \multicolumn{2}{|l|}{ Malawi } & \multicolumn{2}{|l|}{ Uganda } \\
\hline & $\begin{array}{l}\text { Female } \\
(\mathrm{N}=1,279)\end{array}$ & $\begin{array}{l}\text { Male } \\
(\mathrm{N}=1,669)\end{array}$ & $\begin{array}{l}\text { Female } \\
(\mathrm{N}=1,175)\end{array}$ & $\begin{array}{l}\text { Male } \\
(\mathrm{N}=1,249)\end{array}$ & $\begin{array}{l}\text { Female } \\
(\mathrm{N}=890)\end{array}$ & $\begin{array}{l}\text { Male } \\
(\mathrm{N}=1,133)\end{array}$ & $\begin{array}{l}\text { Female } \\
(\mathrm{N}=1,075)\end{array}$ & $\begin{array}{l}\text { Male } \\
(\mathrm{N}=1,288)\end{array}$ \\
\hline \multicolumn{9}{|l|}{ Living arrangement } \\
\hline With both parents/parent figures & 0.88 & 0.91 & 0.65 & 0.65 & 0.80 & 1.21 & $0.56^{*}$ & 1.17 \\
\hline With mother only & 1.26 & 1.05 & 1.21 & 0.53 & 0.82 & 1.03 & 1.02 & 1.25 \\
\hline With father only & 0.78 & 1.04 & 1.16 & 1.33 & 0.41 & 1.73 & 1.10 & 1.37 \\
\hline With none (ref) & 1.00 & 1.00 & 1.00 & 1.00 & 1.00 & 1.00 & 1.00 & 1.00 \\
\hline \multicolumn{9}{|l|}{ Parent/parent figure monitoring } \\
\hline Low & $6.94^{* * *}$ & $5.35 * * *$ & $7.73^{* * *}$ & $4.37^{* * *}$ & 1.49 & $2.36^{* *}$ & $7.28^{* * *}$ & $5.10^{* * *}$ \\
\hline Medium & $2.71^{* * *}$ & $1.74^{* *}$ & $2.70^{* * *}$ & $2.37^{* *}$ & 0.79 & 1.24 & $3.15^{* * *}$ & $2.39^{* * *}$ \\
\hline High (ref) & 1.00 & 1.00 & 1.00 & 1.00 & 1.00 & 1.00 & 1.00 & 1.00 \\
\hline \multicolumn{9}{|c|}{$\begin{array}{l}\text { Parents/parent figures ever talked to } \\
\text { adolescent about sex-related matters }\end{array}$} \\
\hline Yes & 1.08 & 1.33 & 1.34 & 1.04 & 0.95 & $2.19^{* * *}$ & $1.53^{*}$ & 0.95 \\
\hline No (ref) & 1.00 & 1.00 & 1.00 & 1.00 & 1.00 & 1.00 & 1.00 & 1.00 \\
\hline \multicolumn{9}{|c|}{$\begin{array}{l}\text { Parents/parent figures ever gave information } \\
\text { about contraceptive methods }\end{array}$} \\
\hline Yes & 1.11 & 2.98 & 1.07 & 1.64 & 0.67 & 1.00 & 1.31 & 1.58 \\
\hline No (ref) & 1.00 & 1.00 & 1.00 & 1.00 & 1.00 & 1.00 & 1.00 & 1.00 \\
\hline Age & $2.59^{* * *}$ & $3.08^{* * *}$ & $2.35^{* * *}$ & $2.61^{* *}$ & $2.14^{* *}$ & $1.99^{* * *}$ & $1.85^{* *}$ & $2.19^{* * *}$ \\
\hline \multicolumn{9}{|l|}{ Currently in school } \\
\hline Yes & $0.47^{*}$ & $0.47^{*}$ & $0.30^{* * *}$ & $0.51^{*}$ & $0.33^{* * *}$ & $0.46^{* * *}$ & $0.31 * * *$ & $0.46^{* * *}$ \\
\hline No (ref) & 1.00 & 1.00 & 1.00 & 1.00 & 1.00 & 1.00 & 1.00 & 1.00 \\
\hline \multicolumn{9}{|l|}{ Frequency of religious attendance } \\
\hline <once a week (ref) & 1.00 & 1.00 & 1.00 & 1.00 & 1.00 & 1.00 & 1.00 & 1.00 \\
\hline Once a week & 0.67 & 1.05 & 1.32 & 1.22 & 0.63 & 2.05 & 1.36 & $2.03 * *$ \\
\hline >once a week & 0.77 & 1.07 & 1.08 & 1.32 & 0.69 & 1.89 & 1.04 & $2.57^{* * *}$ \\
\hline \multicolumn{9}{|l|}{ Residence } \\
\hline Urban & 1.21 & 0.94 & 1.36 & 1.12 & $1.95^{*}$ & 0.62 & 0.57 & 1.08 \\
\hline Rural (ref) & 1.00 & 1.00 & 1.00 & 1.00 & 1.00 & 1.00 & 1.00 & 1.00 \\
\hline \multicolumn{9}{|l|}{ Household wealth index } \\
\hline Poorest (ref) & 1.00 & 1.00 & 1.00 & 1.00 & 1.00 & 1.00 & 1.00 & 1.00 \\
\hline Second & 0.94 & 1.04 & 1.44 & 0.92 & 1.91 & 1.22 & 1.07 & 1.22 \\
\hline Third & 1.04 & 1.21 & 1.26 & 1.22 & 1.41 & 1.19 & 1.15 & 1.13 \\
\hline Fourth & 1.30 & 1.32 & 1.23 & 0.99 & 1.47 & 0.98 & 1.19 & 1.13 \\
\hline Wealthiest & 1.24 & $2.31^{* *}$ & $0.43^{*}$ & 0.73 & 1.06 & 0.72 & 1.57 & 1.31 \\
\hline
\end{tabular}

tional survey for each country, following a protocol used in the Demographic and Health Surveys. ${ }^{28}$

Bivariate analysis of gender differences in sexual activity, contraceptive use, key dimensions of parenting and background characteristics was conducted using chisquare tests for differences in distribution. Logistic regression analyses were then used to identify associations between the dependent and independent variables, while controlling for all background characteristics; these analyses were conducted separately by gender. Statistical analyses were conducted using STATA version 10, and standard errors were adjusted using the svyset procedure to account for the complex sample design of each survey.

\section{RESULTS}

\section{Bivariate Results}

Levels of self-reported sexual activity among unmarried 15-19-year-olds varied across countries and by gender. Seventeen to $24 \%$ of female adolescents had had sex in the 12 months prior to the survey; the range was wider for males, from $10 \%$ in Ghana to $37 \%$ in Malawi (Table 1, page 75 ). In Malawi and Uganda, significantly higher proportions of males than of females reported having had sex in this period. In contrast, females in Ghana were more likely than males to report sexual activity; this pattern was consistent with Demographic and Health Survey data, which showed that females were more likely to report premarital sex. ${ }^{29}$ Among adolescents who had been sexually active in the last 12 months, $50-56 \%$ of respondents in Burkina Faso, Ghana and Uganda reported using a contraceptive method at last sex, but only 37-41\% reported such use in Malawi. There were no statistically significant differences in contraceptive use by gender in any of the countries.

The proportion of unmarried adolescents who lived with both parents or two parent figures ranged from $40 \%$ to $60 \%$ across the four countries, whereas $22-32 \%$ did not live with any parent or parent figure; most adolescents in the latter category lived with other adults (not shown). 


\begin{tabular}{|c|c|c|c|c|c|c|c|c|}
\hline \multirow[t]{2}{*}{ Variable } & \multicolumn{2}{|c|}{ Burkina Faso } & \multicolumn{2}{|l|}{ Ghana } & \multicolumn{2}{|l|}{ Malawi } & \multicolumn{2}{|l|}{ Uganda } \\
\hline & $\begin{array}{l}\text { Female } \\
(\mathrm{N}=290)\end{array}$ & $\begin{array}{l}\text { Male } \\
(\mathrm{N}=403)\end{array}$ & $\begin{array}{l}\text { Female } \\
(\mathrm{N}=184)\end{array}$ & $\begin{array}{l}\text { Male } \\
(\mathrm{N}=118)\end{array}$ & $\begin{array}{l}\text { Female } \\
(\mathrm{N}=174)\end{array}$ & $\begin{array}{l}\text { Male } \\
(\mathrm{N}=406)\end{array}$ & $\begin{array}{l}\text { Female } \\
(\mathrm{N}=250)\end{array}$ & $\begin{array}{l}\text { Male } \\
(\mathrm{N}=390)\end{array}$ \\
\hline \multicolumn{9}{|l|}{ Living arrangement } \\
\hline With both parents/parent figures & 0.74 & 1.36 & 0.58 & 1.02 & 0.69 & 1.29 & 0.60 & 0.81 \\
\hline With mother only & 0.68 & 1.17 & $0.45^{*}$ & 0.40 & 2.78 & 1.11 & 1.01 & 1.15 \\
\hline With father only & 0.76 & 1.18 & 0.41 & 0.63 & 0.31 & 1.66 & $2.59^{*}$ & 1.59 \\
\hline With none (ref) & 1.00 & 1.00 & 1.00 & 1.00 & 1.00 & 1.00 & 1.00 & 1.00 \\
\hline \multicolumn{9}{|l|}{ Parent/parent figure monitoring } \\
\hline Low & 0.71 & 1.56 & 1.24 & 0.39 & 1.00 & 1.71 & 0.78 & 0.81 \\
\hline Medium & 0.65 & 1.53 & 0.90 & 0.86 & 1.62 & 1.56 & 0.64 & 1.09 \\
\hline High (ref) & 1.00 & 1.00 & 1.00 & 1.00 & 1.00 & 1.00 & 1.00 & 1.00 \\
\hline \multicolumn{9}{|l|}{$\begin{array}{l}\text { Parents/parent figures ever talked to } \\
\text { adolescent about sex-related matters }\end{array}$} \\
\hline Yes & 2.74 & 0.73 & $2.97^{* *}$ & 1.17 & 1.63 & 1.67 & $1.98^{*}$ & $1.85^{*}$ \\
\hline No (ref) & 1.00 & 1.00 & 1.00 & 1.00 & 1.00 & 1.00 & 1.00 & 1.00 \\
\hline \multicolumn{9}{|c|}{$\begin{array}{l}\text { Parents/parent figures ever gave information } \\
\text { about contraceptive methods }\end{array}$} \\
\hline Yes & 1.25 & ne & 1.56 & 0.62 & 0.76 & 0.69 & 1.23 & 0.92 \\
\hline No (ref) & 1.00 & 1.00 & 1.00 & 1.00 & 1.00 & 1.00 & 1.00 & 1.00 \\
\hline Age & 1.43 & 1.47 & 0.94 & 0.93 & $0.35^{*}$ & $2.70^{* * *}$ & 1.46 & $2.08^{* *}$ \\
\hline \multicolumn{9}{|l|}{ Currently in school } \\
\hline Yes & 1.98 & 1.66 & 2.15 & 1.25 & 1.52 & 0.81 & $2.15^{*}$ & 1.27 \\
\hline No (ref) & 1.00 & 1.00 & 1.00 & 1.00 & 1.00 & 1.00 & 1.00 & 1.00 \\
\hline \multicolumn{9}{|l|}{ Frequency of religious attendance } \\
\hline <once a week (ref) & 1.00 & 1.00 & 1.00 & 1.00 & 1.00 & 1.00 & 1.00 & 1.00 \\
\hline Once a week & 0.82 & 1.17 & 1.20 & 1.21 & 3.26 & 2.58 & 1.17 & 1.81 \\
\hline >once a week & 0.82 & 1.09 & 1.64 & 0.71 & 1.82 & 3.31 & 1.46 & 1.72 \\
\hline \multicolumn{9}{|l|}{ Residence } \\
\hline Urban & $3.35^{*}$ & $3.97^{* *}$ & $0.30^{*}$ & 0.86 & $0.28^{*}$ & 1.28 & 2.53 & 1.39 \\
\hline Rural (ref) & 1.00 & 1.00 & 1.00 & 1.00 & 1.00 & 1.00 & 1.00 & 1.00 \\
\hline \multicolumn{9}{|l|}{ Household wealth index } \\
\hline Poorest (ref) & 1.00 & 1.00 & 1.00 & 1.00 & 1.00 & 1.00 & 1.00 & 1.00 \\
\hline Second & 0.93 & 2.27 & 0.81 & 4.14 & 0.80 & 1.75 & 1.03 & 1.31 \\
\hline Third & 1.68 & $3.87^{*}$ & 0.79 & 3.16 & 1.25 & 1.68 & 2.20 & $2.13^{*}$ \\
\hline Fourth & 1.70 & 2.35 & 1.22 & $9.77^{* *}$ & 3.41 & $2.42^{*}$ & 1.18 & $2.57^{* *}$ \\
\hline Wealthiest & 1.49 & $6.69^{* * *}$ & 3.15 & $7.72^{*}$ & $7.81^{*}$ & 2.11 & 2.22 & $4.44^{* *}$ \\
\hline
\end{tabular}

Adolescents in all countries reported moderate to high levels of parental monitoring: For example, $44-75 \%$ of adolescents said their parents or parent figures always knew where they went at night, 34-70\% said their parents always knew what they did in their free time and 40-70\% said their parents always knew who their friends were. However, stark gender differences were evident, as higher proportions of females than of males reported this high level of parental monitoring. The parental monitoring index reflected these single-measure differences, as almost two times as many males as females in each country reported the lowest level of perceived monitoring.

In contrast to the reported levels of monitoring, parental communication about sex-related matters was low: Between $8 \%$ and $38 \%$ of adolescents said a parent or parent figure had ever talked to them about sex, and in three of the countries, males were less likely than females to report such communication. For example, in Uganda, $38 \%$ of females said a parent had talked to them about sexrelated matters, compared with $20 \%$ of males. Parents were even less likely to be information sources regarding contraceptive methods: With the exception of girls in Uganda, no more than $10 \%$ of adolescents said a parent or parent figure had ever given them information about contraception, and in three countries males were less likely to report such communication.

\section{Multivariate Results}

Multivariate analyses showed significant negative associations between monitoring by parents or parent figures and the likelihood that adolescents had had sex in the last 12 months, and this factor had the strongest and most consistent association with sexual activity (Table 2). In all four countries, adolescent males who perceived a low level of 
parental monitoring were more likely to be sexually active than males who perceived a high degree of monitoring (odds ratios, 2.4-5.4). Even a medium level of monitoring (except in Malawi) was associated with increased odds of males being sexually active (1.7-2.4). The same pattern was found for female adolescents in Burkina Faso, Ghana and Uganda: The less they thought their parents or parent figures knew about where they went at night, what they did with their free time and who their friends were, the greater the likelihood that they had had sex in the last year (for low monitoring, 6.9-7.7; for medium monitoring, 2.7-3.2).

Only one significant association was found regarding adolescents' living arrangements and sexual activity: Among Ugandan females, those who lived with both parents or parent figures were less likely than those who lived with none to have had sex in the last year (odds ratio, 0.6). Notably, living with one parent or parent figure, regardless of whether the adolescent was male or female, was not associated with either a higher or a lower risk of sexual activity.

Furthermore, parental communication with adolescents about sex-related matters was not consistently associated with the odds of sexual activity across the four countries; only among Malawian males and Ugandan females was such communication associated with elevated odds of having had sex in the last year (2.2 and 1.5, respectively). No significant associations were found between parents being a source of contraceptive information and their adolescent daughters' or sons' sexual activity.

We generally expected that increased parental involvement-through coresidence, monitoring or communication-would be positively associated with contraceptive use among those adolescents who were sexually active. However, there was no association between parental monitoring and method use at last sex, and associations between the other two dimensions of parenting and use were not consistent across countries (Table 3, page 77). Only two significant associations were found for coresidence: In Uganda, females who lived with their father or father figure only were more likely than those who lived with no parent or parent figure to have used a contraceptive at last sex (odds ratio, 2.6), and in Ghana, females who lived with their mother or mother figure only were less likely to have used a method (0.5). Parent-child communication about sex-related matters was positively associated with contraceptive use for Ghanaian females (3.0) and for Ugandan females and males (2.0 and 1.9, respectively). Finally, no association was found between parents providing information about contraception and adolescents' contraceptive use.

\section{DISCUSSION}

Unmarried adolescents in these four Sub-Saharan African countries generally have (or at least perceive that they have) parents or parent figures who are involved in their lives, and this is especially the case for females. In this study, parents and parent figures were most involved via coresidence, monitoring adolescents' movements at night and during their free time, and knowing who their friends were, but were less involved in actually talking with adolescents about sex-related matters or providing information about contraceptives. Given cultural inhibitions against parent-child conversations regarding sexual issues $^{30}$ and, perhaps as important, negative parental attitudes about unmarried adolescents being sexually active, it is not surprising that only about one in three females and one in five males in Ghana, Malawi and Uganda reported these kinds of conversations. The survey data also revealed that daughters had a much closer connection with parents and parent figures than did sons with respect to monitoring and communication measures. This may be due to their perceived greater vulnerability, or perhaps to the higher social consequences of unprotected sex for unmarried daughters and the cultural double standards regarding sexuality for males and females in these four countries. Results from focus group discussions among adolescents in these countries support the argument that unmarried girls who get pregnant and hence bring shame to a family experience stronger social sanctions than do unmarried boys who get girls pregnant. ${ }^{30,31}$

A high level of perceived parental monitoring was the factor most strongly associated with reduced odds of adolescent sexual activity across all four countries for males and across three countries (the exception being Malawi) for females. The dimensions of coresidence and communication had weaker and less consistent associations with sexual activity. The positive association between parental communication about sex-related matters and adolescents' sexual activity in Malawi and Uganda could be due to discussion after parents had learned that such activity had occurred-the proverbial closing the stable doors after the animals have left. However, because the communication measure lacked specificity, these findings should not be interpreted as conclusive evidence.

In contrast to its association with sexual activity, parental monitoring had no significant association with adolescents' contraceptive use. Parent-child communication about sexual matters was positively associated with method use in only two countries, whereas parents providing information about contraceptives was not associated with protected sex. Furthermore, the negative relationship between a Ghanaian female living with her mother or mother figure only and contraceptive use was puzzling, and could be attributed to factors such as an adolescent's desire not to "disappoint" her mother, since some discussions of contraceptive use involve the parent or parent figure talking to rather than with the young person. ${ }^{13}$

Overall, our results suggest that parental monitoring may be a dimension that is worth strengthening via programmatic efforts-for example, aiding parents in being more supportive of their older adolescents by knowing where they go and whom they spend time with-and that increased monitoring may help adolescents to delay sexual activity (although it may not effectively promote contraceptive use when they do become sexually active). The programmatic implications for improved parent-child 
communication are not definitive given the lack of specificity in the measures used. However, given the relatively low levels of communication about sex-related matters found in this study and the difficulties adolescents (and parents) have in talking about sexuality highlighted in other research, ${ }^{7,18,30}$ there is clearly a need for improved communication about these sensitive issues. Since parentchild communication is often fraught with problems, ${ }^{18}$ other strategies-such as the tradition of using trusted adults in the community to provide information and services to young people (e.g., sengas, or paternal aunts, in Uganda)-should be explored further. Once adolescents are sexually active, they may be better able to protect themselves if they have open, supportive communication channels with parents and parent figures. It may be more beneficial for adolescents to be able to ask parents for advice about sex-related matters or even for help in obtaining methods to avoid unintended pregnancy than for parents to assume a teaching role about methods with their adolescent children.

While our study contributes to the relatively small evidence base on the role of parents in adolescent sexual and reproductive health, it has several limitations. First, because the temporal order of the variables was difficult to ascertain, the cross-sectional data do not allow for any causal interpretation based on family or respondent characteristics, particularly those related to parent-child communication and adolescent sexual and contraceptive behaviors. Additionally, given that important causal factors may have been unmeasured, one cannot rule out the possibility that such factors might influence family-related factors, sexual behavior and contraceptive use.

A second limitation is that the communication dimension was measured in a general way, which leaves uncertain the direction of association (or even opposing influences that may cancel each other). Moreover, the measure of parent-child communication did not identify specific topics (e.g., abstinence or contraceptive use) or tone (e.g., supportive or disciplinary). Also, some adolescents without biological parents or parent figures may have thought that this question was not relevant to them, even though it was phrased to include prior experiences with parents who were no longer around. Furthermore, the question about receiving information on contraceptive methods did not assess the tone of the exchange or the underlying message given, and so in cases where the message was negative, we would expect it to deter adolescents from using contraceptives (i.e., the opposite of what we expected).

A third limitation of the study is that the measures of parental monitoring and communication were based on adolescents' perceptions, which may not reflect what parents or parent figures were actually doing. However, one could also argue that those very perceptions of what is happening directly influence the decisions (or lack thereof) that adolescents make in their lives.

Despite these limitations, the fact that this study found strong positive associations between some dimensions of parenting and adolescents' sexual and contraceptive behaviors suggests that further research into these aspects of parental involvement would be useful. Given the importance of parents in their children's lives and the debate about whether parental involvement is beneficial to adolescents' sexual and reproductive health, one overarching conclusion is that some aspects of parental involvement, but probably not all, likely play key roles in helping adolescents establish and maintain healthy sexual and reproductive lives. Programs would do well to take parental involvement elements into consideration in their efforts to help young people protect themselves against HIV and unintended pregnancy, as well as other sexual and reproductive health risks.

\section{REFERENCES}

1. Rodgers K, Parenting process related to sexual risk-taking behaviors of adolescent males and females, Journal of Marriage and Family, 1999, 61(1):99-109

2. World Health Organization (WHO), Helping Parents in Developing Countries Improve Adolescents' Health, Geneva: WHO, 2007.

3. Wight $D$, Williamson $L$ and Henderson M, Parental influences on young people's sexual behaviour: a longitudinal analysis, Journal of Adolescence, 2006, 29(4):473-494.

4. Ross DA, Dick B and Ferguson J, Preventing HIV/AIDS in Young People: A Systematic Review of the Evidence from Developing Countries, WHO Technical Report Series, Geneva: WHO, 2006, No. 938.

5. WHO, Summaries of Projects in Developing Countries Assisting the Parents of Adolescents, Geneva: WHO, 2007.

6. Diop NJ et al., Improving the Reproductive Health of Adolescents in Senegal, Washington, DC: Population Council/FRONTIERS Program, 2004.

7. Kiragu K et al., Straight Talk Campaign in Uganda: Parent Survey, Washington, DC: Horizons/Straight Talk Foundation, 2007.

8. Miller KS and Vandenhoudt H, Youth prevention activities in western Kenya: the Families Matter program, paper presented at the Interagency Youth Working Group meeting, Washington, DC, Dec. 6, 2007.

9. Borawski EA et al., Parental monitoring, negotiated unsupervised time, and parental trust: the role of perceived parenting practices in adolescent health risk behaviors, Journal of Adolescent Health, 2003, 33(2):60-70,

10. Li X, Stanton B and Feigelman S, Impact of perceived parental monitoring on adolescent risk behavior over 4 years, Journal of Adolescent Health, 2000, 27(1):49-56.

11. Ngom P, Magadi MA and Owuor T, Parental presence and adolescent reproductive health among the Nairobi urban poor, Journal of Adolescent Health, 2003, 33(5):369-377.

12. Karim AM et al., Reproductive health risk and protective factors among unmarried youth in Ghana, International Family Planning Perspectives, 2003, 29(1):14-24.

13. Kumi-Kyereme A et al., Influence of social connectedness, communication and monitoring on adolescent sexual activity in Ghana African Journal of Reproductive Health, 2007, 11(3):133-147.

14. Babalola S, Tambashe BO and Vondrasek C, Parental factors and sexual risk-taking among young people in Côte d'Ivoire, African Journal of Reproductive Health, 2005, 9(1):49-65.

15. Bettinger JA et al., Does parental involvement predict new sexually transmitted diseases in female adolescents? Archives of Pediatrics $E$ Adolescent Medicine, 2004, 158(7):666-670.

16. DiClemente RJ et al., Parental monitoring: association with ado- 
lescents' risk behaviors, Pediatrics, 2001, 107(6):1363-1368.

17. Roche KM, Ahmed S and Blum RW, Enduring consequences of parenting for risk behaviors from adolescence into early adulthood, Social Science \& Medicine, 2008, 66(9):2023-2034.

18. Awusabo-Asare K, Bankole A and Kumi-Kyereme A, Views of adults on adolescent sexual and reproductive health: qualitative evidence from Ghana, Occasional Report, New York: Guttmacher Institute, 2008, No. 34

19. Joint United Nations Programme on HIV/AIDS (UNAIDS), 2008 Report on the Global AIDS Epidemic, Geneva: UNAIDS, 2008.

20. Mensch BS, Grant MJ and Blanc AK, The changing context of sexual initiation in Sub-Saharan Africa, Population and Development Review, 2006, 32(4):699-727.

21. Cleland J and Ali MM, Sexual abstinence, contraception, and condom use by young African women: a secondary analysis of survey data, Lancet, 2006, 368(9549):1788-1793

22. Khan S and Mishra V, Youth Reproductive and Sexual Health, DHS Comparative Reports, Calverton, MD, USA: Macro International, 2008, No. 19

23. Awusabo-Asare Ket al., Adolescent sexual and reproductive health in Ghana: results from the 2004 National Survey of Adolescents, Occasional Report, New York: Guttmacher Institute, 2006, No. 22.

24. Guiella G and Woog V, Sante sexuelle et reproductive des adolescents au Burkina Faso: résultats d'une enquête nationale en 2004, Occasional Report, New York: Guttmacher Institute, 2006, No. 21.

25. Munthali A et al., Adolescent sexual and reproductive health in Malawi: results from the 2004 National Survey of Adolescents, Occasional Report, New York: Guttmacher Institute, 2006, No. 24

26. Neema S et al., Adolescent sexual and reproductive health in Uganda: results from the 2004 National Survey of Adolescents, Occasional Report, New York: Guttmacher Institute, 2006, No. 25.

27. Bankole A et al., Sexual behavior, knowledge and information sources of very young adolescents in four Sub-Saharan African countries, African Journal of Reproductive Health, 2007, 11(3):28-34.

28. Rutstein SO and Johnson $\mathrm{K}$, The DHS Wealth Index, DHS Comparative Reports, Calverton, MD, USA: ORC Macro, 2004, No. 6.

29. Curtis SL and Sutherland EG, Measuring sexual behaviour in the era of HIV/AIDS: the experience of Demographic and Health Surveys and similar enquiries, Sexually Transmitted Infections, 2004, 80(Suppl. 2):ii22-ii27.

30. Amuyunzu-Nyamongo M et al., Qualitative evidence on adolescents' views of sexual and reproductive health in Sub-Saharan Africa, Occasional Report, New York: Alan Guttmacher Institute, 2005, No. 16.

31. Bleek W, Avoiding shame: the ethical context of abortion in Ghana, Anthropological Quarterly, 1981, 54(4):203-209.

\section{RESUMEN}

Contexto: Los padres tienen influencia en la salud sexual y reproductiva de los adolescentes, pero las pruebas de esto en África Subsahariana son limitadas. Se necesita en la región una mejor comprensión de las relaciones entre las diferentes dimensiones de la paternidad, la actividad sexual reciente y el uso de anticonceptivos.

Métodos: La recolección de datos se realizó en 2004 a partir de encuestas representativas a nivel nacional aplicadas a jóvenes de 12-19 años de edad en Burkina Faso, Ghana, Malaui y Uganda. Mediante análisis bivariado, se comparó las diferencias de género entre adolescentes solteros de 15-19 años de edad para dos resultados-haber tenido relaciones sexuales en los últimos 12 meses y, entre los que habian tenido relaciones en ese período, haber usado anticonceptivos en la última relación sexual. Mediante análisis de regresión logística multivariado, se realizó la identificación de las asociaciones entre estos resultados y el hecho de compartir la residencia con los padres o las figuras paternas, el monitoreo por los padres y la comunicación entre padres e hijos.

Resultados: Las y los adolescentes solteros reportaron niveles de moderados a altos de monitoreo por los padres y bajos niveles de comunicación entre padres e hijos acerca de temas sexuales. En todos los países, los hombres adolescentes que reportaron un bajo nivel de monitoreo estuvieron en alto riesgo de haber tenido relaciones sexuales en el último año (razones de momios, 2.4-5.4), como lo fueron sus contrapartes femeninas en tres de los países (6.9-7.7). La comunicación con los padres se asoció positivamente con la actividad sexual en los hombres malauies y las mujeres ugandesas (2.2 y 1.5, respectivamente). El monitoreo de los padres no se asoció con el uso de anticonceptivos en la última relación sexual en ningún país, mientras que la comunicación entre padres e hijos se asoció con ese uso en mujeres ghanesas (3.0) y entre adolescentes ugandeses de ambos géneros (1.9-2.0).

Conclusión: Los programas para mejorar la salud sexual y reproductiva de las y los adolescentes deben incluir dimensiones de participación de los padres que puedan fortalecer las metas específicas de cambio de conductas del programa.

\section{RÉSUMÉ}

Contexte: Les parents exercent une influence sur la santé sexuelle et génésique des adolescents. Les données relatives à la question pour l'Afrique subsaharienne sont cependant limitées. Il serait utile de mieux comprendre le rapport entre les différentes dimensions du rôle parental, d'une part, et, d'autre part, l'activité sexuelle et pratique contraceptive récentes dans la région.

Méthodes: Les données ont été recueillies en 2004 dans le cadre d'enquêtes nationalement représentatives auprès de jeunes de 12 à 19 ans du Burkina Faso, du Ghana, du Malawi et d'Ouganda. L'analyse bivariée a servi à comparer les différences entre les sexes pour deux résultats parmi les jeunes non mariés de 15 à 19 ans: rapports sexuels durant les 12 derniers mois et, parmi ceux qui avaient eu des rapports pendant cette période, pratique contraceptive lors des derniers rapports. L'analyse de régression logistique multivariée identifie les associations entre ces résultats et la co-résidence avec les parents ou figures parentales, la surveillance parentale et la communication parents-enfants.

Résultats: Les adolescents non mariés déclarent des niveaux de surveillance parentale moyens à élevés et de faibles niveaux de communication parents-enfants sur les questions de nature sexuelle. Dans tous les pays, les adolescents de sexe masculin qui déclarent un faible niveau de surveillance sont associés à un risque élevé d'avoir eu des rapports sexuels durant la dernière année écoulée (rapports de probabilités, 2,4-5,4). Il en va de même pour leurs homologues féminines dans trois des pays à l'étude (6,9-7,7). La communication avec les parents est associée positivement à l'activité sexuelle chez les garçons 
du Malawi et les filles d'Ouganda (2,2 et 1,5, respectivement). La surveillance parentale n'est pas associée à la pratique contraceptive lors des derniers rapports sexuels. En revanche, la communication parents-enfants l'est chez les filles du Ghana $(3,0)$ et les adolescents ougandais des deux sexes $(1,9$ et 2,0, respectivement).

Conclusion: Les programmes visant à améliorer la santé sexuelle et génésique des adolescents doivent inclure des dimensions d'implication parentale aptes à renforcer leurs objectifs spécifiques de changement comportemental.

\section{Acknowledgments}

The authors thank the researchers from the Protecting the Next Generation project, from which the survey data originated: Akwasi Kumi-Kyereme of the University of Cape Coast, Ghana; Christine Ouedraogo and Georges Guiella, formerly of the Institut Supérieur des Sciences de la Population, Burkina Faso; Stella Neema and Richard Kibombo of the Makerere Institute of Social Research, Uganda; Alister Munthali and Sidon Konyani, Centre for Social Research, Malawi; Alex Ezeh and Eliya Zulu of the African Population and Health Research Center, Kenya; Nyovani Madise, University of Southampton, UK; and Susheela Singh and Ann Moore of the Guttmacher Institute, USA. Funding for this project was provided by the Bill \& Melinda Gates Foundation, the Rockefeller Foundation and the U.S. National Institute of Child Health and Human Development (grant 5 R24 HD043610). This research was presented at the conference "Investing in Young People's Health and Development: Research That Improves Policies and Programs," Abuja, Nigeria, April 27-29, 2008.

Author contact: abiddlecom@guttmacher.org 